\section{Smoke and mirrors: the perceived benefits of continued tobacco use among current smokers}

\author{
Hugh Klein,1,2 Claire E. Sterk, 1 \\ Kirk W. Elifson \\ ${ }^{1}$ Rollins School of Public Health, Emory \\ University, Atlanta, GA; \\ 2Kensington Research Institute, \\ Silver Spring, MD, USA
}

\section{Abstract}

Despite $50+$ years of public health efforts to reduce smoking rates in the United States, approximately one-fifth of the adults living in this country continue to smoke cigarettes. Previous studies have examined smokers' risk perceptions of cigarette smoking, as well as the perceived benefits of quitting smoking. Less research has focused on the perceived benefits of smoking among current cigarette smokers. The latter is the main focus of the present paper. Questionnaire-based interviews were conducted with a community-based sample of 485 adult current cigarette smokers recruited from the Atlanta, Georgia, metropoli$\tan$ area between 2004 and 2007. Active and passive recruiting approaches were used, along with a targeted sampling strategy. Results revealed that most current cigarette smokers perceive themselves to experience benefits as a result of their cigarette use, including (among others) increased relaxation, diminished nervousness in social situations, enjoyment of the taste of cigarettes when smoking, and greater enjoyment of parties when smoking. Perceiving benefits from cigarette smoking was associated with a variety of tobacco use measures, such as smoking more cigarettes, an increased likelihood of chain smoking, and overall negative attitude toward quitting smoking, among others. Several factors were associated with the extent to which smokers perceived themselves to benefit from their tobacco use, including education attainment, the age of first purchasing cigarettes, the proportion of friends who smoked, hiding smoking from others, being internally-oriented regarding locus of control, and self-esteem.

\section{Introduction}

For more than 50 years now, public health campaigns have disseminated information to the American public about the dangers associ- ated with smoking. Overwhelmingly, their message has been that using tobacco is unhealthy and poses a variety of health risks to smokers and to those around them. These campaigns have succeeded in altering societal norms regarding the way people think and feel about smoking. Consequently, there has been a dramatic reduction in the proportions of American adults who use tobacco today compared to the $1960 \mathrm{~s}$, when tobacco use peaked in the United States. ${ }^{1}$

Despite these anti-smoking campaigns, about one-fifth of the U.S. adult population continues to smoke and the reduction in smoking rates seems to have leveled off. 2 Thus, it is important that we learn from people who continue to smoke about the reasons for their continued cigarette use. Research on the perceived benefits of smoking has been limited and, largely, focused on adolescents, who report that smoking makes people look cool, leads them to be more popular, makes them look more grown up, and helps them to feel more relaxed. These positive perceptions of smoking have been shown to be related to a greater likelihood of tobacco use and intentions to smoke in the near future. ${ }^{3,4}$

Less has been written about the subject of perceived benefits of smoking among adult smokers. Interestingly, in the few studies that have examined this issue among adults, many of the same perceived benefits just mentioned have been cited as being applicable to adult smokers. 5 Additionally, findings from adult samples have also shown the perceived benefits of smoking to include the perception that smoking reduces depression, feels pleasurable, reduces anxiety, and helps people to focus their thoughts. ${ }^{6,7}$

Developing a better understanding of the positive ways in which smokers view their tobacco use may represent a critical step in the ongoing public health campaign to reduce the societal harms of smoking. In the present study, based on a sample of adult persistent smokers, we examine three main research questions. First, how prevalently held are perceptions of the benefits of smoking among persistent smokers? Second, how, if at all, does perceiving smoking to be personally beneficial relate to people's actual tobacco use behaviors and health problems resulting from those behaviors? Third, what factors are associated with having an overall greater perception that smoking is beneficial? The last question in particular is of importance, we believe, because the answer(s) can be used to develop informed intervention efforts at the individual level and broader-based anti-smoking prevention campaigns.
Correspondence: Hugh Klein, Kensington Research Institute, 401 Schuyler Road, Silver Spring, MD 20910, USA.

Tel.: + 1.301.588.8875.

E-mail: hughk@aol.com, hughkhughk@yahoo.com

Key words: smoking, perceptions, attitudes toward smoking, perceived benefits of smoking.

Contributions: the authors contributed equally.

Conflict of interests: the authors declare no potential conflict of interests.

Received for publication: 22 March 2013.

Revision received: 14 May 2013.

Accepted for publication: 16 May 2013.

This work is licensed under a Creative Commons Attribution NonCommercial 3.0 License (CC BYNC 3.0).

(c) Copyright H. Klein et al., 2014

Licensee PAGEPress, Italy

Health Psychology Research 2014; 2:1519

doi:10.4081/hpr.2014.1519

\section{Materials and Methods}

\section{Subjects and design}

The data presented in this study were collected in Atlanta, Georgia between September 2004 and July 2007 as part of the Persistent Smokers Project (PSP).

[Although the data for this study are a few years old, recent data from the Centers for Disease Control and Prevention ${ }^{2}$ indicate that the challenges currently facing adult persistent smokers have not changed since the completion of the Persistent Smokers Project. This is especially true for smokers residing in the South region of the United States. ${ }^{2}$ Smoking rates have plateaued in recent years, ${ }^{2}$ and no new strategies have been effective at reducing smoking rates during the years since the Persistent Smokers Project was undertaken. Consequently, the authors believe that this study and its findings remain relevant today, as the playing field for the battle to reduce smoking and its attendant problems has changed very little during the few years that have elapsed since this study's data were collected].

This was a community-based nonprobability sample, and was not derived from clinical or other institutional settings. To be eligible, the participants had to be aged 18 years or older and reside in the Atlanta metropolitan area. As a study of persistent smokers, study participants had to have smoked at least 100 cigarettes during their lifetime [which is consistent with the National Health Interview Survey (NHIS) classification as ever smoked $]^{8}$ and 
have smoked in the last week (which is consistent with the NHIS classification as current smoker).

Participant recruitment involved purposive sampling, including a combination of active and passive recruitment techniques. This approach to participant recruitment was based largely on the principles of targeted sampling and ethnographic mapping. ${ }^{9,10}$ It is common for techniques such as these to be used whenever the research population of interest is considered to be a hard to recruit or a hidden population as was the case with the present study. These sampling techniques have been used by other researchers to study smoking behaviors and are considered acceptable by most scholars in the field.11,12 Using a short screening form, for the active recruitment approach, potential study participants were screened in the setting where they were recruited, such as near office buildings or other work locations, at restaurants, in social entertainment settings, in parks, and in other public settings. Passive recruitment involved posting flyers in local venues such as stores, restaurants, and community centers. Interested individuals, who called the project phone line listed on the flyers, initially were screened over the phone using the same short form used in the active recruitment. Two-thirds of the respondents were brought into the study via active recruitment, with the remaining one-third being identified through passive recruitment. We did not identify any significant difference in the sample characteristics or in the outcome variables based on the recruitment strategy.

Once a person was identified as eligible, the staff member described the study and time required to participate. The most common reason for ineligibility was having smoked an insufficient number of cigarettes to qualify, either during the person's lifetime or during the preceding week. The interviews took place at a mutually-convenient location, such as one of the project offices, the respondent's home, a local restaurant or coffee shop, or at community centers. Additional information was provided on the nature of the study, the time required, and the informed consent and other confidentiality procedures. The questionnaire contained items covering the respondent's background characteristics, smoking behaviors, attitudes, and opinions, as well as items about alcohol and other drugs, a health inventory, and self and identity items. The average length of the interview as 90 minutes and respondents received 20 US Dollars (\$) as compensation for their time and participation.

The targeted sampling design and data collection procedures, ${ }^{10}$ yielded a sample of 485 smokers. The sample provided a diverse crosssection of Atlanta smokers well-suited to exploring our research questions regarding the factors associated with persistent smok- ing. Compared to national data reported by the Centers for Disease Control and Prevention, the study sample included more women and was better educated. Otherwise, the sample reflected the characteristics of smokers nationally. 13

\section{Measures used}

The questionnaire used in this research was developed specifically for this study. Parts of it were derived from standardized scales that have been used successfully in other studies of adult smokers. Those are noted below, wherever applicable. Other parts of the questionnaire were developed based on formative research conducted by the lead investigators prior to implementation of the Persistent Smokers Project study. Still other parts of the questionnaire were developed based on consultations with various experts in the tobacco/smoking field, incorporating key constructs recommended by them based on their experience and expertise. The innovative approach to studying smoking behaviors utilized in the Persistent Smokers Project required that these unique measures be developed to supplement extant measures.

The main outcome measure of interest in these analyses is people's overall perceptions of benefits from smoking. This is a scale measure derived from 16 component items which were adapted from the work of Copeland $e t$ $a l .{ }^{14}$ and Myers et al. ${ }^{15}$ The scale includes such perceived smoking-related benefits as being calmed down by cigarettes, reductions in nervousness when smoking, being energized by smoking, enjoying parties more when using tobacco, enjoying conversations more when smoking, enjoying the feeling of holding a cigarette, feeling more like part of a group when smoking, and feeling more relaxed around other people when smoking, among others. All component items were asked in Likert fashion, and scale scores could range from 16 to 80 . The scale was found to be reliable (Cronbach's alpha=0.81).

In the part of the analysis examining whether the perceived benefits of smoking were related to tobacco use outcomes, the aforementioned scale was the independent variable and numerous smoking-related measures were used as dependent variables. These included: the number of cigarettes smoked in a typical week (continuous measure), amount of tobacco smoked when sick/ill (ordinal measure), the frequency of needing a cigarette to function (ordinal measure), the frequency of making special trips just to get cigarettes (ordinal measure), the frequency of chain smoking (ordinal measure), the frequency of smoking more than intended (ordinal measure), taking steps to get the most out of one's smoking (continuous scale measure, Cronbach's alpha $=0.68$ ), the extent of viewing oneself negatively as a result of smoking (continuous scale measure comprised by 26 items, Cronbach's alpha $=0.82$ ), the number of reasons the person had for wanting to quit smoking (continuous scale measure comprised by 14 items, Kuder-Richardson $20=0.81$ ), the number of reasons the person had for wanting to cut down on tobacco use (continuous scale measure comprised by 12 items, KuderRichardson $_{20}=0.84$ ), and the person's overall attitudes toward quitting smoking (continuous scale measure comprised by 18 items, Cronbach's alpha=0.71).

For the final part of the analysis, in which the emphasis was on identifying the factors associated with having an overall greater perception that smoking is beneficial, several types of potential predictors were examined: demographic differences, tobacco use-related items, and measures of psychological and psychosocial functioning. Demographic variables were included because numerous studies have found smoking-related perceptions to vary based on such characteristics as race,16,17 age, 17 and gender. ${ }^{18}$ Likewise, many studies have documented a link between perceptions relating to smoking behaviors and actual tobacco use practices. ${ }^{19,20}$ Therefore, we examined several smoking influence items as potential predictor measures. Finally, some published research has also documented that smokers' perceptions of the benefits and drawbacks of smoking vary based on their psychosocial profiles, such as their levels of impulsiveness, self-esteem, or depression, ${ }^{21-23}$ thereby meriting the inclusion of measures of this type in our analysis as well.

Five demographic variables were examined: gender (male versus female), age (in years), race (African American versus members of other racial groups), educational attainment (less than high school education versus high school graduate or greater), and marital status (involved versus not involved with someone).

Several smoking influence measures were considered, as well. These included age of first cigarette use (continuous measure), age of first cigarette purchase (continuous measure), ever lied to a steady partner about one's intentions of quitting smoking (yes/no), having a parent who suffered physical consequences from smoking (yes/no), having another family member who suffered physical consequences from smoking (yes/no), the proportion of one's friends who smoke (ordinal measure), having nonsmoking friends make comments about one's smoking (7-item scale measure, Kuder-Richardson $20=0.74$ ), hiding one's tobacco use from others (yes/no), and the number of health risks perceived to be associated with smoking (6-item scale measure, Cronbach's alpha=0.71).

Measures of psychological and psychosocial functioning were also examined by using a vari- 
ety of standardized scale measures, including: sociability (derived from the Social Avoidance and Distress Scale) ${ }^{24}$ (11 items; Cronbach's alpha=0.89), self-consciousness in social situations (constructed from a modified version of Scheier and Carver's Self-Consciousness Scale) ${ }^{25}$ (8 items; Cronbach's alpha=0.83), social isolation (11 items; Cronbach's alpha $=0.87$ ), perceived predictability/randomness of events in one's life (derived from Schuessler's Doubt about Self-Determination Scale $)^{26}$ (12 items; Cronbach's alpha $=0.75$ ), and self-esteem (Rosenberg's Self-Esteem Scale) ${ }^{27}$ (10 items; Cronbach's alpha=0.86).

\section{Analysis}

In the first part of the analysis, the goal was to examine people's perceptions of the benefits of smoking and the prevalence of positive perceptions of the benefits to be derived by smoking. This information is reported by the use of descriptive statistics. For the remainder of the paper, readers may find it helpful to bear in mind that, as a psychosocial measure, perceived benefits of smoking is conceptualized as an endogenous variable analytically. By that, we mean that it both affects/underlies some outcome measures (specifically, actual tobacco use practices), in which instances perceived benefits of smoking serves as an independent variable, and is affected/predicted by other measures (e.g., demographic characteristics, early-life experiences with smoking, other measures of psychological/psychosocial functioning), in which instances perceived benefits of smoking serves as a dependent variable. These different roles of the perceived benefits of smoking measure are reflected in the Part 2 analysis (examining how the perceived benefits of smoking relate to actual smoking practices) and in the Part 3 analysis (examining the factors associated with perceiving more/fewer benefits from smoking).

In the second part of the analysis, the goal was to examine the relationship between perceiving smoking to yield personal benefits and various tobacco-related outcome measures. All of the dependent variables here were either continuous scale measures or ordinal measures with more than four response options. Accordingly, these analyses all entailed the use of zero-order correlation coefficients, shown in Table 1 by reporting Pearson's $r$ statistics.

In the third part of the analysis, bivariate analyses were conducted to learn which items were found to be related to study participants' perceptions of the extent to which they derived positive benefits from their cigarette smoking. Whenever the independent variable was dichotomous in nature (e.g., gender, hiding one's smoking from others, past-year physical abuse), Student's $t$ tests were performed to ascertain whether the comparison groups differed from one another on the dimension in question. Whenever the independent variable was continuous in nature (e.g., religiosity, age of first cigarette use, self-esteem), the bivariate analyses entailed the use of correlation coefficients. Subsequently, items that were found to be associated with the perception of deriving benefits from smoking were entered into a multiple regression equation, to determine which ones contributed to the understanding of perceived smoking benefits when the effects of the other measures were taken into account. Items that were non-significant were removed from the equation in stepwise fashion, until a final best fit model containing only statistically-significant measures was derived. Throughout this paper, results are reported as statistically significant whenever $\mathrm{P}<0.05$.

\section{Results}

\section{Sample}

Slightly more than one-half of the study participants (56.8\%) were male. Most were either Caucasian (54.6\%) or African American (39.0\%). The median age was 34 (range: 18-70, mean: $36.4, \mathrm{SD}=12.3$ ). This is a fairly well-educated sample, with $34.2 \%$ of the respondents having completed college and an additional $40.6 \%$ having attended college without completing it. Although most (55.1\%) of the study participants were employed on a full-time basis, substantial proportions of them were working on a part-time basis (32.9\%) or unemployed (12.0\%). Respondents were relatively evenly split between those who were single $(42.7 \%)$ or involved in a marital-type relationship (44.5\%). Approximately one person in six (16.5\%) selfidentified as gay, lesbian, or bisexual.

\section{Perceived benefits of smoking}

Slightly more than one-third of the study participants (37.7\%) could be described as having overall positive beliefs regarding the benefits they perceived to derive from their smoking (i.e., mean score ranging from 3.51 to 5.00 on the $1-5$ scale). Most respondents (57.4\%) were relatively average in terms of the extent to which they said that their smoking led them to experience various benefits (mean score ranging from 2.51 to 3.50 on the 1-5 scale). Very few of the people studied (4.9\%) had what would be described most accurately as negative beliefs regarding the benefits derived from their tobacco use (i.e., mean scores ranging from 1.00 to 2.50 on the 1 5 scale). Overall, this sample scored slightly more positive than average with regard to members' perceptions of the extent to which they benefitted by smoking (mean: $3.37, \mathrm{SD}=0.50$ ).

Specific information about the nature of the positive perceptions people held with regard to their smoking is presented in Table 2. Of the 16 benefits derived from smoking that we examined, 7 were endorsed by a majority of the study participants; and most of these items were endorsed by a substantial majority of them. For example, $88.8 \%$ of the smokers studied said that smoking helps them to satisfy their nicotine cravings. Nearly as many people said that cigarettes calmed them down when they are angry (82.7\%), that smoking helped them to cope with their worries $(81.9 \%)$, that smoking helped them to calm down when they were feeling nervous about something (80.0\%), and/or that smoking helped them to kill time when there was nothing to do (76.\%). Nearly two-thirds of the people sampled said that they enjoyed parties more when they were smoking (63.3\%), and more than one-half $(56.5 \%)$ said that they enjoyed the taste sensation of smoking. On some of the other dimensions of perceived benefit, when a majority of persons did not endorse a particular item, the perceived benefiters outnumbered those who did not share such perceptions by a substantial margin. This was true for items pertaining to cigarettes making people feel good ( $42.9 \%$ versus $28.8 \%$ ), finding the mere handling of a cigarette to be a pleasurable experience ( $47.1 \%$ versus $34.3 \%$ ), and feeling like a part of a group when they are around other smokers (43.7\% versus $33.6 \%)$.

Table 1. Zero-order correlations between perceiving benefits of smoking and actual tobacco-related outcomes.

\begin{tabular}{lcc} 
Dependent variable & Pearson's r & P \\
Number of cigarettes smoked per week & 0.20 & $<0.001$ \\
Amount smoked when sick enough to be in bed all day & 0.21 & $<0.001$ \\
\hline Frequency of needing a cigarette to function normally & 0.43 & $<0.001$ \\
Frequency of making special trips to purchase cigarettes & 0.25 & $<0.001$ \\
\hline Frequency of chain smoking & 0.23 & $<0.001$ \\
Frequency of smoking more cigarettes than intended & 0.15 & $<0.001$ \\
\hline Doing things to get the most out of smoking & 0.17 & $<0.001$ \\
Viewing one's smoking and/or oneself negatively & -0.31 & $<0.001$ \\
\hline Number of reasons for wanting to quit smoking & 0.02 & 0.589 \\
\hline Number of reasons for wanting to reduce tobacco use & 0.05 & 0.302 \\
\hline Overall attitudes toward quitting smoking & -0.43 & $<0.001$ \\
\hline
\end{tabular}




\section{Perceived benefits of smoking and actual tobacco use behaviors}

Not surprisingly, people's perceptions of the benefits they derived from smoking were related to their tobacco use behaviors (Table 1). For example, the greater the benefits they perceived smoking to have for them in their daily lives, the greater the number of cigarettes participants typically smoked each week $\left(F_{1,483 d f}=19.84\right.$, $\mathrm{P}<0.001$ ). Likewise, the greater the benefits people said they derived from their tobacco use, the more they tended to smoke when sick/ill enough to remain in bed for the day $\left(F_{1,482 d f}=22.97, \mathrm{P}<0.001\right)$. The more beneficial aspects of smoking they perceived themselves to experience, the more frequently participants reported needing a cigarette just to function properly $\left(F_{1,483 d}=109.33, \mathrm{P}<0.001\right)$ and the more often they made special trips to purchase cigarettes $\left(F_{1,483 d f}=3.283, \mathrm{P}<0.001\right)$. The greater the number of benefits they perceived themselves to derive from their tobacco use, the more often respondents reported chain smoking $\left(F_{1,482 d f}=25.86, \mathrm{P}<0.001\right)$ and the more frequently they smoked more than they intended $\left(F_{1,483 d}=11.71, \mathrm{P}<0.001\right)$. Additionally, the more beneficial they said that smoking was for them, the greater the number of things smokers did to get the most out of their smoking, $\left(F_{1,477 d f}=14.33\right.$, $\mathrm{P}<0.001$ ). The more negatively respondents felt about their smoking habits, the fewer the number of benefits they said they got from using tobacco $\left(F_{1,483 d f}=50.85, \mathrm{P}<0.001\right)$. Conversely, the more positively study participants felt about the idea of stopping smoking, the fewer the number of benefits they perceived themselves to derive from cigarette use $\left(F_{1,483 d f}=112.19\right.$, $\mathrm{P}<0.001)$. Among the very few items not found to be related to perceived benefits from smoking were the number of reasons given for wanting to quit smoking $\left(F_{1,483 d f}=0.29, \mathrm{NS}\right)$ and the number of reasons given for wanting to cut down on tobacco use $\left(F_{1,479 d r}=1.07, \mathrm{NS}\right)$.

\section{Factors associated with perceiving benefits from smoking}

The next part of the analysis entailed examining how people's perceptions of the benefits they derived from smoking differed based on various personal characteristics, such as their demographic profile, tobacco-related items, and psychological and psychosocial functioning. Regarding the former, as a general rule, participants' perceptions of the benefits derived from their tobacco use did not differ much based on their demographic characteristics. One exception was found, and that was for educational attainment: people who had not completed high school or the equivalent reported experiencing fewer benefits from smoking than their bettereducated counterparts did $(t=2.21, \mathrm{P}=0.028)$. African Americans were slightly more negative in their overall perceptions than members of other racial groups were $(t=1.72, \mathrm{P}=0.087)$. People's perceptions of the benefits experienced as a result of their tobacco use did not differ based on their gender $\left(t=1.15\right.$, NS), age $\left(F_{1,483 d t}=0.77\right.$, NS), or marital status $(t=0.32, \mathrm{NS})$.

In contrast, for the most part, the tobacco userelated items were found to be related to people's perceptions of the benefits experienced as a result of their smoking. The younger people were when they had their first cigarette, the more benefits they considered themselves to receive when they smoked $\left(F_{1,483 d f}=5.65\right.$, $\mathrm{P}=0.018$ ). Similarly, the younger they were when they purchased their first cigarette, the more positive aspects they ascribed now to their tobacco use $\left(F_{1,483 d f}=14.36, \mathrm{P}<0.001\right)$. The larger the proportion of the person's friends who were smokers, the more benefits the study participants perceived themselves to benefit from smoking $\left(F_{1,481 d}=12.25, \mathrm{P}<0.001\right)$. Somewhat counterintuitively, the more complaints people's nonsmoking friends made to them about their tobacco use, the more these individuals perceived themselves to benefit from smoking $\left(F_{1,455 d}=4.84, \mathrm{P}=0.028\right)$. Moreover, smokers who tried to hide their cigarette use from others were more positive in their perceptions of smoking's benefits to them than were their peers who did not try to keep their tobacco use hidden from others $(t=2.05, \mathrm{P}=0.041)$. There was a tendency

for people who perceived tobacco use to be associated with greater health risks to believe that smoking yielded fewer benefits to them $\left(F_{1,483 d f}=3.07, \mathrm{P}=0.081\right)$. Lying to a steady partner about their intentions to quit smoking was not found to be related to the extent to which people perceived themselves to benefit from their tobacco use $(t=1.33$, NS). The same was true with regard to whether or not people had a parent $(t=0.80$, NS) or another family member $(t=1.15, \mathrm{NS})$ who was ill or suffering from smoking-related illnesses.

Most of the psychological and psychosocial measures examined were found to be related to the extent to which people perceived their smoking to yield them positive benefits. The less selfconscious people were when in the presence of others, the fewer the benefits they perceived themselves to experience as a result of their smoking $\left(F_{1,483 d f}=17.50, \mathrm{P}<0.001\right)$. In addition, the more people perceived the events in their lives to have a random, unpredictable quality to them, the fewer the number of benefits they perceived themselves to derive from tobacco use $\left(F_{1,483 d f}=9.66, \mathrm{P}=0.002\right)$. Self-esteem was found to be related inversely to a perception of receiving benefits from tobacco use $\left(F_{1,483 d f}=20.94\right.$, $\mathrm{P}<0.001)$. Sociability $\left(F_{1,483 d f}=1.89\right.$, NS $)$ and social isolation $\left(F_{1,483 d f}=1.99\right.$, NS) were not

Table 2. Perceived benefits of smoking.

\begin{tabular}{lccc}
\hline Perceived benefit from smoking & Agreed, \% & Neutral, \% & Disagreed, \% \\
Cigarettes calm me down when angry & 82.7 & 10.7 & 6.6 \\
Smoking calms me down when nervous & 80.0 & 11.3 & 8.7 \\
\hline Smoking energizes me & 25.0 & 28.4 & 46.6 \\
Cigarettes make me feel good & 42.9 & 28.3 & 28.8 \\
\hline I enjoy parties more when smoking & 63.3 & 18.0 & 18.7 \\
Conversations are more special if we're all smoking & 29.8 & 20.2 & 50.0 \\
\hline Smoking helps to cope with worries & 81.9 & 9.7 & 8.4 \\
Enjoy the taste sensation of smoking & 56.5 & 22.1 & 21.4 \\
\hline Smoking helps keep me feeling happy & 25.8 & 30.7 & 43.5 \\
Smoking satisfies nicotine cravings & 88.8 & 6.2 & 5.0 \\
\hline Just handling a cigarette is pleasurable & 47.1 & 18.6 & 34.3 \\
Smoking helps keep my weight down & 38.8 & 26.4 & 34.8 \\
\hline I feel like a part of a group when I'm around smokers & 43.7 & 22.7 & 33.6 \\
Smoking helps to kill time & 76.5 & 9.5 & 14.0 \\
\hline I enjoy the steps I take to light up & 28.6 & 37.9 & 33.5 \\
I feel more at ease with others if I have a cigarette & 38.1 & 28.9 & 33.0 \\
\hline
\end{tabular}

Table 3. Multivariate analysis examining the factors associated with the perception of deriving positive benefits from smoking.

\begin{tabular}{lcc} 
Independent variable & b $(\beta)$ & P \\
Less than high school education & $0.20(0.18)$ & $<0.001$ \\
Age of first purchase of cigarettes & $0.02(0.18)$ & $<0.001$ \\
\hline Proportion of friends who smoke & $-0.26(0.13)$ & 0.003 \\
Hiding one's smoking from others & $-0.11(0.10)$ & 0.021 \\
\hline Extent of viewing events as randomly occurring & $0.10(0.11)$ & 0.028 \\
Self-esteem & $0.15(0.17)$ & $<0.001$ \\
\hline
\end{tabular}


found to be associated with the perception of benefitting from smoking.

Table 3 presents the findings of the multivariate analysis. In total, six items were found to be associated with the extent to which people perceived smoking to be beneficial to them. First, people who had not completed high school or its equivalent viewed themselves as experiencing significantly fewer benefits from smoking than their better-educated counterparts did $(\mathrm{P}<0.001)$. Second, the younger people were when they first purchase a cigarette, the more positive benefits they said they derived from their tobacco use now $(\mathrm{P}<0.001)$. Third, the greater the proportion of their friends who were smokers, the greater the number of perceived benefits of smoking was $(\mathrm{P}<0.01)$. Fourth, persons who reported trying to hide their tobacco use from others said that they got more benefits from smoking than did their counterparts who were not trying to keep their smoking secret $(\mathrm{P}<0.05)$. Fifth, the more people perceived the events in their lives to occur randomly rather than with predictability and explanation, the fewer the number of benefits they perceived themselves to derive from tobacco use $(\mathrm{P}<0.05)$. Sixth, the better participants' self-esteem was, the more negatively they viewed smoking in their lives $(\mathrm{P}<0.001)$. Together, these six items explained $12.6 \%$ of the total variance.

\section{Discussion and Conclusions}

Perhaps one of the most striking findings obtained in this research was the sizable proportion of study participants who had positive perceptions regarding the benefits that smoking has for them. Substantial majorities of the people taking part in this research felt that cigarettes calm them down when they are angry or when they are feeling nervous about something, and that smoking helps them to cope with their worries. Additionally, most of the people surveyed said that smoking helps them to pass time, that they enjoy social events like parties more if they are smoking, and/or that they simply enjoy the taste sensation they get from smoking. More than one-third of the people sampled reported that, overall, they felt that they derived a variety of benefits from smoking. This compares to fewer than 5\% of them saying that, on balance, smoking was not beneficial to them. With all of the health information that has been provided to smokers during the past $50+$ years about the potential harms that may result from smoking, it is rather surprising to discover that, even in a population of persistent smokers such as the one on which the present research is based, the perceived benefits of smoking outweighed the perceived adverse consequences of smoking by a ratio of nearly 8:1. It stands to reason that, if people perceive smoking to be beneficial to them, and if they do not perceive it to be harmful to them, they will be unlikely to want to quit smoking. Our finding supports this notion, and highlights the need to work with smokers to diminish the benefits they perceive themselves to derive from their tobacco use behaviors (noted by other researchers as well). ${ }^{28,29}$

Coinciding with the preceding, we also found perceiving oneself to benefit from smoking was related to a number of cigarette smoking behaviors. Included among these were the number of cigarettes smoked per day, the frequency of chain smoking, doing things to get the most out of one's tobacco use, smoking more cigarettes than intended, among other outcomes. Again, these relationships are not surprising, but they demonstrate a fairly strong link between having positive perceptions of smoking and actual tobacco use-related outcomes.

Having established that a sizable proportion of the study participants perceived smoking to be beneficial to them, and then having established that this perception was related to their actual tobacco use practices, we turned our attention to an examination of the factors associated with having a positive overall impression of the role(s) that smoking plays in smokers' lives. Based on a multivariate analysis, we identified six factors that contributed uniquely to the extent to which people perceived smoking to benefit them. These factors merit further discussion.

First, people who were lower in education (i.e., high school diploma or less) were less likely than their better-educated peers to adhere to positive perceptions of the benefits of smoking. This finding stands in contrast to most published reports, which have found an inverse relationship between educational attainment and tobacco-related measures such as cigarette usage. ${ }^{30,31}$ Thus, we are left with the task of trying to explain why it may be that better-educated adults perceive more benefits to result from their smoking behaviors than their less-well-educated counterparts. One possibility that occurs to us is that cigarette advertising, which glamorizes smoking and makes it appear to be an innocuous behavior in which wealthy, healthy people engage, $32-34$ may be more effective at reaching better-educated persons because they relate to the advertising media messages better than people who do not resemble tobacco ads' models. If such media-promulgated tobacco messages are effective at reaching better-educated persons, then this may help to explain why these individuals, as a group, may perceive themselves to derive benefits from smoking. Another possible explanation that occurs to us is that better-educated persons may be more apt to ignore anti-smoking messages or to dismiss them as less relevant to them than their notas-well-educated counterparts. Research on this topic is lacking. But we believe that it is not unreasonable to expect that anti-smoking campaigns and grassroots anti-tobacco programs may be targeting lower-education persons more often than higher-education persons, simply because of the national trends statistics showing greater tobacco use among less-well-educated people.

Another of the main predictors of perceiving benefits to result from smoking identified in the present study was a younger age of first cigarette purchase. Younger age of beginning smoking has been linked with a reduced likelihood of quitting smoking, ${ }^{35,36}$ an increased likelihood of rapid progression into nicotine dependence, 35,37 and more days missed at work due to illness, ${ }^{35}$ among other adverse outcomes. ${ }^{38}$ The present study's finding of a link between early onset tobacco purchases (which can be used as a proxy measure for the initiation of regular tobacco use) and positive perceptions of the benefits of smoking is consistent with these findings, and it expands upon them by demonstrating yet one more way in which early-onset tobacco use may be of concern. It also highlights the need to consider people who began using tobacco at an early age a target group in need of specific prevention and intervention efforts with regard to smoking cessation.

A third noteworthy finding generated by the present study is that, the greater the percentage of their friends who smoked cigarettes, the more people tended to perceive themselves to derive benefits from smoking. In all likelihood, having tobacco-using friends helps smokers not to feel isolated socially as a result of their tobacco use. Moreover, smoking is likely to be a shared activity among persons who have friends who smoke, as is going to restaurants and other public venues where smoking is permitted. This finding has important and direct implications for smoking cessation: it suggests that helping smokers to modify their social networks, either by spending more time with nonsmoking friends or by spending less time with tobacco-using friends (or both), is likely to yield benefits with regard to the way they think about continuing to smoke and whether or not they will, indeed, continue to smoke. Numerous community-based anti-smoking initiatives have emphasized the value of quitting buddies and social supports as key ways to terminate smoking behaviors, ${ }^{39-41}$ and these programs have met with great success.

The data also revealed that hiding one's smoking from others was associated with greater adherence to the perception that smoking is more beneficial than detrimental to oneself. Keeping one's tobacco use behaviors secret from others is usually something that is reported by underage smokers who do not wish 
their parents to find out that they have begun using tobacco, ${ }^{42}$ or by persons who work in professions where it looks bad for them to smoke (e.g., nurses, physicians). ${ }^{43}$ Further research is needed to understand the phenomenon of hiding one's smoking behaviors, and to ascertain the extent to which this is related to the increasing stigmatization of cigarette smoking in our society.

Another intriguing finding obtained by the present research is that people whose locus of control is internally- rather than externally-oriented perceive their smoking to yield more benefits to them than do their counterparts who are more externally-oriented, and who perceive the things that happen to them to be out of their own personal control. Previous research has shown that smokers find smoking less rewarding when they perceive their tobacco use to be out of their control versus within their personal control. ${ }^{44}$ Moreover, having a greater internal locus of control has been found to be related to greater success in facilitating smoking cessation. 45 It very well may be that a greater internal locus of control is linked with having more positive perceptions of the personal benefits derived from smoking because internally-oriented persons perceive their smoking to be something that they themselves control.

Finally, we confirmed that higher selfesteem was associated with a diminished perception of deriving benefits from smoking. Other published reports have shown an inverse relationship between self-esteem and tobacco use. ${ }^{46-48}$ Our work complements these study findings and extends them, by demonstrating one more way in which low selfesteem may have an impact upon smoking practices, namely, by influencing how people feel about the benefits they derive from using cigarettes. The main implication of this finding is that anti-smoking campaigns and behavioral intervention efforts targeting individual smokers might achieve greater success if they try to incorporate self-esteem enhancement skills components into their program efforts. Our findings suggest that improvements in self-esteem might lead to changes in how people feel about their tobacco use, and that in turn might lead to changes in their actual smoking practices.

We would like to acknowledge three potential limitations of this research. First, the data collected as part of this study of adult persistent smokers were all based on uncorroborated selfreports. Therefore, the extent to which respondents underreported or over-reported their involvement in various smoking-related behaviors is unknown. In all likelihood, the self-reported data can be trusted, as numerous authors have noted that persons in their smoking studies have provided reasonably accurate information about their tobacco-using behaviors. ${ }^{49-51}$
A second possible limitation pertains to recall bias. Respondents were asked to report about their beliefs, attitudes, and behaviors during the past 30 days or the past year, depending upon the measure in question. These time frames were chosen specifically i) to incorporate a large enough amount of time in the risk behavior questions' time frames so as to facilitate meaningful variability from person to person, and ii) to minimize recall bias. The exact extent to which recall bias affected the data cannot be assessed, although other researchers collecting various types of smoking-related data have reported that recall bias is sufficiently minimal that its impact upon study findings is likely to be small. ${ }^{52}$

A third possible limitation of these data comes from the sampling strategy used. All interviews were conducted in the Atlanta, Georgia metropolitan area. There may very well be local or regional influences or subcultural differences between these persons and those residing elsewhere that could affect the generalizability of the data.

\section{References}

1. Centers for Disease Control and Prevention. Surveillance for selected tobacco-use behaviors: United States, 1900-1994. Available from: http://www.cdc.gov/mmwr/ preview/mmwrhtml/00033881.htm

2. Centers for Disease Control and Prevention. Vital signs: Current cigarette smoking among adults aged $\geq 18$ years: United States, 2005-2010. MMWR Morb Mortal Wkly Rep 2011;60:1207-12.

3. Epstein JA, Griffin KW, Botvin GJ. A model of smoking among inner-city adolescents: the role of personal competence and perceived social benefits of smoking. Prev Med 2000;31:107-14.

4. Halpern-Felsher BL, Biehl M, Kropp RY, Rubinstein ML. Perceived risks and benefits of smoking: differences among adolescents with different smoking experiences and intentions. Prev Med 2004;39:559-67.

5. World Bank Group. Economics of tobacco control. 2001. Available from: http://web. worldbank.org/WBSITE/EXTERNAL/TOPICS/EXTHEALTHNUTRITIONANDPOPULATION/EXTETC/0,,menuPK:376607 pagePK :149018 piPK:149093 theSitePK:376601, 00.html. Accessed on May 6, 2013.

6. Hutcheson TD, Greiner KA, Ellerbeck EF, et al. Understanding smoking cessation in rural communities. J Rural Health 2008; 24:116-24.

7. Lucksted A, Dixon LB, Sembly JB. A focus group pilot study of tobacco smoking among psychosocial rehabilitation clients. Psychiatr Serv 2000;51:1544-8.
8. Centers for Disease Control and Prevention. NHIS. Adult tobacco use information: smoking status recodes. 2009b. Available from: http:/www. cdc.gov/nchs/ nhis/tobacco/tobacco_recodes.htm

9. Sterk C. Building bridges: community involvement in HIV and substance abuse research. Drugs So. 1999;14:107-21.

10. Watters J, Biernacki P. Targeted sampling: options for the study of hidden populations. Soc Probl 1989;36:416-30.

11. McElroy JA, Everett KD, Zaniletti I. An examination of smoking behavior and opinions about smoke-free environments in a large sample of sexual and gender minority community members. Nicotine Tob Res 2011;13:440-8.

12. Stevens W, Thorogood M, Kayikki S. Costeffectiveness of a community anti-smoking campaign targeted at a high risk group in London. Health Promot Int 2002;17:43-50.

13. Centers for Disease Control and Prevention. A program for early release of selected estimates from the National Health Interview Survey. 2009a. Available from: http://www.cdc.gov/nchs/data/nhis/ earlyrelease/ER_Booklet.htm

14. Copeland AL, Brandon TH, Quinn EP. The smoking consequences questionnaireadult: measurement of smoking outcome expectancies of experienced smokers. Psychol Assess 1995;7:484-94.

15. Myers MG, McCarthy DM, MacPherson L, Brown SA. Constructing a short form of the smoking consequences questionnaire with adolescents and young adults. Psychol Assess 2003;15:163-72.

16. Bock BC, Niaura RS, Neighbors CJ, et al. Differences between latino and non-latino white smokers in cognitive and behavioral characteristics relevant to smoking cessation. Addict Behav 2005;30:711-24.

17. Lyna P, McBridge C, Samsa G, Pollak KI. Exploring the association between perceived risks of smoking and benefits of quitting: who does not see the link? Addict Behav 2002;27:293-307.

18. McKee SA, O'Malley SS, Salovey P, et al. Perceived risks and benefits of smoking cessation: Gender-specific predictors of motivation and treatment outcome. Addict Behav 2005;30:423-35.

19. Correia CJ, Ballard SD, Henslee AM, Irons JG. Perceived consequences of cigarette use among college students. Addict Behav 2006;31:1490-5.

20. Kreslake JM, Wayne GF, Connolly GN. The menthol smoker: tobacco industry research on consumer sensory perception of menthol cigarettes and its role in smoking behavior. Nicotine Tob Res 2008; 10:705-15.

21. Coggins CRE, Murrelle EL, Carchman RA, Heidbreder C. Light and intermittent ciga- 
rette smokers: a review (1989-2009) Psychopharmacology 2009;207:343-63.

22. Floyd AHL, Westmaas JL, Targhetta V, Moyer A. Depressive symptoms and smokers' perceptions of lung cancer risk: moderating effects of tobacco dependence. Addict Behav 2009;34:154-63.

23. Woodruff SI, Conway TL, Edwards CC. Sociodemographic and smoking-related psychosocial predictors of smoking behavior change among high school smokers. Addict Behav 2008;33:354-8.

24. Watson D, Friend R. Measurement of social-evaluative anxiety. J Consult Clin Psychol 1969;33:448-57.

25. Scheier MF, Carver CS. The self-consciousness scale: a revised version for use with general populations. J Appl Soc Psychol 1985;15:687-99.

26. Schuessler K. Measuring social life feelings. San Francisco: Jossey-Bass; 1982.

27. Rosenberg M. Society and the adolescent self-image. Princeton, NJ: Princeton University Press; 1965.

28. Bishop AJ, Marteau TM, Hall S, et al. Increasing women's intentions to stop smoking following an abnormal cervical smear test result. Prev Med 2005;41:179-85.

29. Martin RA, Rohsenow DJ, MacKinnon SV, et al. Correlates of motivation to quit smoking among alcohol dependent patients in residential treatment. Drug Alcohol Depend 2006;83:73-8.

30. Gilman SE, Martin LT, Abrams DB, et al. Educational attainment and cigarette smoking: a causal association? Int J Epidemiol 2008;7:615-24.

31. Lawlor DA, Batty D, Morton SMB, et al. Childhood socioeconomic position, educational attainment, and adult cardiovascular risk factors: the Aberdeen children of the 1950s cohort study. Am J Public Health 2005;95:1245-51.

32. Arnett JJ. Talk is cheap: the tobacco companies' violations of their own cigarette advertising code. J Health Commun 2005; 10:419-31.
33. Boyd CJ, Boyd TC, Cash JL. Why is Virginia slim: women and cigarette advertising. Int Q Community Health Educ 1999-2000; 19:19-31.

34. Pierce JP. Tobacco industry marketing, population-based tobacco control, and smoking behavior. Am J Prev Med 2007; $33: s 327-34$.

35. Lando HA, Haddock CK, Robinson LA, et al. Ethnic differences in patterns and correlates of age of initiation in a population of Air Force recruits. Nicotine Tob Res 2000;2:337-44.

36. Pisinger C, Vestbo J, Borch-Johnsen K, Jorgensen T. Smoking cessation intervention in a large randomised populationbased study: the Inter99 Study. Prev Med 2005;40:285-92.

37. Storr CL, Zhou H, Liang K, Anthony JC. Empirically derived latent classes of tobacco dependence syndromes observed in recent-onset tobacco smokers: epidemiological evidence from a national probability sample survey. Nicotine Tob Res 2004;6:533-45.

38. Weitzman ER, Chen Y. The co-occurrence of smoking and drinking among young adults in college: national survey results from the United States. Drug Alcohol Depend 2005;80:377-86.

39. Andrews J0, Felton G, Wewers ME, et al. The effect of a multi-component smoking cessation intervention in African American women residing in public housing. Res Nurs Health 2007;30:45-60.

40. Helving TM, Sobell LC, Sobell MB, Simco ER. Smokers' narrative accounts of quit attempts: aids and impediments to success. Psychol Addict Behav 2006;20:219-24.

41. Nollen NL, Catley D, Davies G, et al. Religiosity, social support, and smoking cessation among urban African American smokers. Addict Behav 2005;30:1225-9.

42. Foraker RE, Patten CA, Lopez KN, et al. Beliefs and attitudes regarding smoking among young adult Latinos: a pilot study. Prev Med 2005;41:126-33.
43. Sarna L, Bialous SA, Wewers ME, et al. Nurses, smoking, and the workplace. Res Nurs Health 2005;28:79-90.

44. Catley D, Grobe JE. Using basic laboratory research to understand scheduled smoking: a field investigation of the effects of manipulating controllability on subjective responses to smoking. Health Psychol 2008;27:s189-96.

45. Williams GC, McGregor HA, Sharp D, et al. Testing a self-determination theory intervention for motivating tobacco cessation: supporting autonomy and competence in a clinical trial. Health Psychol. 2006; 25:91-101.

46. Croghan IT, Bronars C, Patten CA, et al. Is smoking related to body image satisfaction, stress, and self-esteem in young adults? Am J Health Behav 2006;30:322-33.

47. Kendler KS, Neale MC, Sullivan P, et al. A population-based twin study in women of smoking initiation and nicotine dependence. Psychol Med 1999;29:299-308.

48. Song H, Fish M. Demographic and psychosocial characteristics of smokers and nonsmokers in low-socioeconomic status rural Appalachian two-parent families in southern West Virginia. J Rural Health 2006;22:83-7.

49. Johnson TP, Mott JA. The reliability of selfreported age of onset of tobacco, alcohol, and illicit drug use. Addiction 2001;96: 1187-98

50. Klein JD, Thomas RK, Sutter EJ. Selfreported smoking in online surveys: prevalence estimate validity and item format effects. Med Care 2007;45:691-5.

51. Stanton CA, Papandonatos G, LloydRichardson EE, Niaura R. Consistency of self-reported smoking over a six-year interval from adolescence to young adulthood. Addiction 2007;102:1831-9.

52. Pomerleau OF, Pomerleau CS, Mehringer $\mathrm{AM}$, et al. Validation of retrospective reports of early experiences with smoking. Addict Behav 2005;30:607-11. 